Environ. Sci. Technol., 40 (6), 1934 -1941, 2006.

Copyright @ 2006 American Chemical Society

\title{
Comparison of Analytical Techniques for Dynamic Trace Metal Speciation in Natural Freshwaters
}

\author{
Laura Sigg, *† Frank Black, $†$ Jacques Buffle, $\$$ Jun Cao, $†$ Rob Cleven, $\perp$ \\ William Davison, $¥$ Josep Galceran, Peggy Gunkel, 3 Erwin Kalis, $\bowtie$ David \\ Kistler, $\mathbf{\dagger}$ Michel Martin, $\$$ \\ Puy, , Willem van Riemsdijk, $\bar{\otimes}$ Erwin Temminghoff,, Mary-Lou Tercier- \\ Waeber, $\$$ Stefanie Toepperwien, $\dagger$ Raewyn M. Town, $\circ$ Emily Unsworth, $\neq$ \\ Kent $W$. Warnken, $¥$ Liping Weng, $\bowtie$ Hanbin Xue, $t$ and Hao Zhang $¥$
}

Eawag, Swiss Federal Institute for Aquatic Science and Technology, P.O. Box 611, $\mathrm{CH}-8600$ Duebendorf, Switzerland, and Department of Environmental Science, University of Lancaster, Lancaster LA1 4YQ, United Kingdom, and Chimie Analytique et Biophysicochimie de Environnment, CABE, University of Geneva, Section de Chimie - Sciences II, 30 Quai Ernest-Ansermet, CH-1211 Geneva 4, Switzerland, and Laboratory for Analytical Chemistry, Rijksinstituut voor Volksgezondheid en Milieu, Antonie van Leeuwenhoeklaan 9, P.O. Box 1, Bilthoven, 3721 BA, The Netherlands, and Departament de Química, Universitat de Lleida, Avda. Rovira Roure 177, E-25198 Lleida, Spain, and Sub-Department of Soil Quality, Wageningen University, Dreijenplein 10, P.O. Box 9101, Wageningen, 6703 HB, The Netherlands, and Department of Chemistry, University of Southern Denmark, Campusvej 55, DK-5230 Odense, Denmark

\begin{abstract}
:
Several techniques for speciation analysis of $\mathrm{Cu}, \mathrm{Zn}, \mathrm{Cd}, \mathrm{Pb}$, and $\mathrm{Ni}$ are used in freshwater systems and compared with respect to their performance and to the metal species detected. The analytical techniques comprise the following: (i) diffusion gradients in thin-film gels (DGT); (ii) gel integrated microelectrodes combined to voltammetric in situ profiling system (GIME-VIP); (iii) stripping chronopotentiometry (SCP); (iv) flow-through and hollow fiber permeation liquid membranes (FTPLM and HFPLM); (v) Donnan membrane technique (DMT); (vi) competitive ligand-exchange/stripping voltammetry (CLE-SV). All methods could be used both under hardwater and under softwater conditions, although in some cases problems with detection limits were encountered at the low total concentrations. The detected $\mathrm{Cu}, \mathrm{Cd}$, and $\mathrm{Pb}$ concentrations decreased in the order DGT $\geq$ GIME-VIP $\geq$ FTPLM $\geq$ HFPLM $\approx$ DMT (>CLE-SV for Cd), detected Zn decreased as DGT $\geq$ GIME-VIP and Ni as DGT > DMT, in agreement with the known dynamic features of these techniques. Techniques involving in situ measurements (GIME-VIP) or in situ exposure (DGT, DMT, and HFPLM) appear to be appropriate in avoiding artifacts which may occur during sampling and sample handling.
\end{abstract}


Environ. Sci. Technol., 40 (6), 1934 -1941, 2006.

\section{Introduction}

The speciation of trace metals in natural freshwaters plays a crucial role in determining their reactivity, mobility, bioavailability, and toxicity $(1,2)$. Measurements of either total, or "dissolved" (e.g., following $0.45 \mu \mathrm{m}$ filtration) metal concentrations provide little insight to the potential ecotoxicological impacts. Studies of metal uptake by aquatic organisms, especially algae, under controlled conditions have, in many cases, indicated that the activities of free metal ions control the uptake and effects of metals (free ion activity model, FIAM, and biotic ligand model, BLM) (1-4). However, detailed examination of the fluxes and kinetics involved in metal uptake by organisms showed that the FIAM is a simplified limiting case of the general dynamic situation, in which fluxes of compounds and the relative time scales of processes, e.g., the rate of complex dissociation must be considered (5-7).

There is a need for dynamic analytical techniques able to routinely measure parameters that are reliable predictors of bio-availability and bio-uptake and, thus, of the potential ecotoxicological risk. Ideally such measurements should be made in situ to avoid sampling and sample handling artifacts. This is a considerable challenge; techniques must be suf ficiently robust to withstand field deployment, provide adequate sensitivity (subnanomolar), and furnish a signal that can be quantitatively interpreted in terms of the chemical species present. In natural waters, trace metals will be associated with a range of inorganic and organic ligands, resulting in a heterogeneous distribution of complexes with a range of stabilities, kinetic labilities, and molecular sizes $(8,9)$. No single analytical method can provide a detailed description of all the species involved, but will measure a certain proportion of the total complexes that lie within a given characteristic thermodynamic and kinetic window (10).

A dynamic analytical sensor is characterized by its (i) response time, which is determined by the thickness of the diffusion layer, and its (ii) accumulation time, $t_{\text {acc }}$ i.e., the length of time over which pollutant species are accumulated in (loaded onto) the sensor prior to quantification. The signal resulting from the accumulation step represents an integra tion of all fluctuations in the test medium during this time period, $t_{\mathrm{acc}}$. We report here on the application of a suite of devices that measure fluxes over a range of well-defined time scales from which complementary metal speciation data can be obtained (10). Some equilibriumbased methods are also examined.

The following techniques were utilized and compared in this study (for detailed descriptions see refs 10-12): (i) diffusive gradients in thin-film gels (DGT) (1315); (ii) gel integrated microelectrode arrays (GIME) installed in a voltammetric in situ profiling system or a voltammetric in-line analyzer for in-field square wave stripping voltammetric measurements (GIME-VIP and GIME-VIA-FIELD) (16-19);

(iii) stripping chronopotentiometry (SCP) at gel integrated single microelectrodes $(20,21)$; (iv) flow-through and hollow fiber permeation liquid membranes (FTPLM and HFPLM) (22-25); (v) Donnan membrane technique (DMT) $(26,27)$; (vi) competitive ligand-exchange stripping voltammetry or adsorption stripping voltammetry (CLE-SV or CLE-AdSV, ref 28). DGT, GIME, and SCP are dynamic techniques spanning a range of response times, whereas DMT and PLM may be used either as equilibrium or dynamic techniques, and CLE-SV is an equilibrium based method. The key concepts involved in quantitative interpretation of signals furnished by this suite of methods have been presented (10) and are briefly recalled here. For the equilibrium-based DMT and CLE-SV methods, kinetic features must still be considered to ascertain whether equilibrium is attained within the given time scale $(29,30)$. For the dynamic techniques, it is generally 
Environ. Sci. Technol., 40 (6), 1934 -1941, 2006.

the free metal species $M$ which is consumed at the sensor surface. The overall flux of $M$ to the analytical interface results from the coupled diffusion and kinetics of interconversion between $M$ and its various species in the complex system. Labile species are those for which the kinetic flux arising from dissociation of the complex into $M$ is much greater than the diffusion-limited flux. Lability is, thus, an operationally defined parameter that depends on the effective time scale of the analytical technique. The dynamic species measured in each case are those which are both labile and mobile for the given technique, and will include free metal ions and labile complexes in the size range of a few nanometers.

DGT, GIME-VIP or GIME-VIA-FIELD, and SCP measure the dynamic metal species according to their characteristic time scale (10). Using PLM, either the free metal ions or the dynamic species are determined, respectively, according to the permeability criterion (see Supporting Information, Table S1) $(22,24,31)$. Free metal ions are obtained from DMT and CLE-SV measurements (10). The GIMEVIP/VIA-Field technique allows in situ or on-site measurements of the trace metals. DGT-samplers, HFPLM- and DMT-devices are exposed in situ, and the collected metals are subsequently measured in the laboratory. SCP, FTPLM, and CLE-SV are carried out in the laboratory on discrete water samples.

All these techniques are compared here for the first time on real freshwater samples. Two field campaigns were carried out by the participating laboratories, during which field measurements, field exposures, and laboratory-based measurements in water samples were carried out. One field campaign took place at hardwater sites (Lake Greifen and Stream Furtbach) in Switzerland, and the other one at a softwater site (River Wyre) in England. The objectives of this study are to evaluate the reliability and performance of these methods and to interpret the trace metal speciation based on comparison of the operationally dynamic proportions of trace metals (copper, zinc, cadmium, lead, and nickel) measured by these various methods under freshwater conditions. In a companion publication, the experimental results are compared to modeling of metal speciation (32).

\section{Materials and Methods}

Sampling Sites. The fieldworks at Lake Greifen and Stream Furtbach in Switzerland were carried out from 2 to 5 September 2003. Lake Greifen is a small eutrophic lake located in Eastern Switzerland near Zurich. Thermal stratification of Lake Greifen lasts from about May to December, with a thermocline located around $10 \mathrm{~m}$ depth. Samples were taken at the deepest point of the lake from the oxic epilimnion at 2.5 and $5 \mathrm{~m}$ depth, in which intensive algal photosynthesis is taking place.

The Furtbach is a small stream located in Eastern Switzerland near Zurich, which flows for approximately $10 \mathrm{~km}$ through the Furttal Valley, with an average discharge of about $0.4 \mathrm{~m}^{3} \mathrm{~s}^{-1}$. Its depth at the sampling site was 0.4-0.5 m during the sampling period. The trace metal concentrations in the Furtbach are influenced by the vicinity of metal-handling industries and the presence of metalcontaminated sediments.

The River Wyre was sampled at Garstang in Lancashire, NW England, from 19 to 22 April 2004. The Wyre is an unpolluted river with high concentrations of dissolved organic carbon (DOC), due to its drainage from a moorland area partly covered with peat. The water level was high and colored by dissolved organic matter due to rainfall the day before the fieldwork started $(6 \mathrm{~mm}$ rain recorded 
Environ. Sci. Technol., 40 (6), 1934 -1941, 2006.

by the metrological office field station Hazlerigg DCNN7236 situated a few kilometers north of the fieldwork site).

Sampling. Water samples from Lake Greifen at 2.5 and $5 \mathrm{~m}$ depths were collected into polyethylene $10-\mathrm{dm}^{3}$ containers using polytetrafluoroethylenecoated Go-Flo water samplers attached to a stainless steel (zinc-free) cable. Temperature, oxygen content, $\mathrm{pH}$, and conductivity were measured in situ using a combined probe (WTW Multi Set 340i).

Water samples from Furtbach were collected by peristaltic pumping using polytetrafluoroethylene tubes into polyethylene $10-\mathrm{dm}^{3}$ containers on 3 and 5 September 2003. Water samples were also collected, into polypropylene $1-\mathrm{dm}^{3}$ bottles, automatically every hour by an autosampling device (ISCO 6700 portable sampler, 24 samples over $48 \mathrm{~h}$ ). This device, together with an acid washed, plastic covered polypropylene container, was installed in a protected area located at about $10 \mathrm{~m}$ from the stream bank. Temperature, $\mathrm{pH}$, and dissolved oxygen were measured on-site.

Water samples from the Wyre, collected to determine dissolved trace metals, were filtered on-site (nucleopore $0.45 \mu \mathrm{m}$ ) into acid washed $15-\mathrm{cm}^{3}$ Nalgene bottles, using acid-washed plastic syringes and in-line filter holders, and immediately acidified. Bulk water samples were also collected by submerging acid cleaned $4-\mathrm{dm}^{3}$ plastic bottles and removing and replacing the cap underwater. Samples for trace metal analysis were acidified with suprapure nitric acid. Temperature, $\mathrm{pH}$, and dissolved oxygen were measured on-site.

Sample Handling and Trace Metal Clean Conditions. All samplers, containers, filters, and filtration devices for trace metal analysis were carefully cleaned with nitric acid and Nanopure water (from a Barnstead ultrapure water system) and were protected during transport with plastic bags. All handling was performed with plastic gloves.

The $10-\mathrm{dm}^{3}$ samples from Lake Greifen and Furbach and 4- $\mathrm{dm}^{3}$ samples from Wyre were filtered in the laboratory under clean-bench conditions, within a few hours of col lection, using a polysulfone filtration device (Nalgene) and $0.45-r \mathrm{~m}$ filters (cellulose nitrate filters, Sartorius). Samples for measurements of total dissolved metal concentrations were immediately acidified to $\mathrm{pH} 2$ with suprapure $\mathrm{HNO}_{3}$. Samples for speciation measurements were left at their original $\mathrm{pH}$ and stored at $4{ }^{\circ} \mathrm{C}$ in the dark. Subsamples were taken for major ion analysis.

Measurements of Total Metal Concentrations. Total dissolved metal concentrations were measured by four laboratories using ICP-MS (inductively coupled plasma-mass spectrometry). The measurements at Eawag were carried out for Lake Greifen and Furtbach with a Perkin-Elmer Elan 5000, and for River Wyre using an Element2, Thermo Finnigan. Rhodium was used as an internal standard. The limits of determination were $0.15 \mathrm{nM} \mathrm{Cu}, 0.3 \mathrm{nM} \mathrm{Zn,} 0.04 \mathrm{nM} \mathrm{Cd}$, $0.05 \mathrm{nM} \mathrm{Pb}, 1 \mathrm{nM} \mathrm{Ni}$, and $1 \mathrm{nM} \mathrm{Mn}$. Trace metal concentrations were measured in Lancaster using a Thermo X-7 (Thermo Elemental, Cheshire, UK). Rhodium was used as an internal standard. The limits of determination were $0.1 \mathrm{nM} \mathrm{Cu}, 1 \mathrm{nM}$ $\mathrm{Zn}, 0.004 \mathrm{nM} \mathrm{Cd}, 0.001 \mathrm{nM} \mathrm{Pb}, 0.2 \mathrm{nM} \mathrm{Ni}, 0.5 \mathrm{nM} \mathrm{Al}, 0.2 \mathrm{nM} \mathrm{Mn}$, and $0.3 \mathrm{nM} \mathrm{Fe}$. ICP-MS measurements in Geneva were carried out with a Hewlett-Packard 4500, using rhodium and rhenium as internal standards. The limits of determination were $0.4 \mathrm{nM} \mathrm{Cu}, 0.2 \mathrm{nM} \mathrm{Zn}, 0.05 \mathrm{nM} \mathrm{Cd}$, and $0.03 \mathrm{nM} \mathrm{Pb}$. The measurements at the Soil Quality Department, Wageningen University were carried out with a

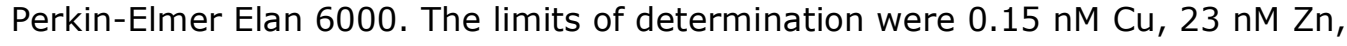


Environ. Sci. Technol., 40 (6), 1934 -1941, 2006.

$0.01 \mathrm{nM} \mathrm{Cd}$, and $0.06 \mathrm{nM} \mathrm{Pb}$. The accuracy of the ICP-MS measurements was controlled on a regular basis, using internal reference samples.

The laboratories in Duebendorf, Lancaster, and Geneva all use the certified reference material SLRS-4 (river water reference material, National Research Council, Canada) to check the ICP-MS measurements for accuracy and precision. The recoveries are usually within the confidence limits of the reference material. If they are not within this range, the instrument calibration is checked. The laboratory in Wageningen uses for reference a solution containing $630 \mathrm{nM} \mathrm{Cu}$, $622 \mathrm{nM}$ Zn, $357 \mathrm{nM} \mathrm{Cd}$, and $193 \mathrm{nM} \mathrm{Pb}$.

Major Ion and DOC Measurements. Methods for major ion and DOC measurements are described in the Supporting Information.

DGT Sampling and Handling. Three sets of DGT samplers (named below as DGT Lancaster, DGT Duebendorf, and DGT Bilthoven) were used, which were prepared and handled separately according to the recommendations of the labora tory in Lancaster $(14,33)$. Details of the gel preparation and sample handling are described in the Supporting Information. DGT samplers were deployed in Lake Greifen at 2.5 and $5 \mathrm{~m}$ depth from 2 to 4 September 2003, in Furtbach and Wyre at a depth of about $20 \mathrm{~cm}$ for 1-4 days periods.

In Situ/On-Site GIME Measurements. GIME voltam metric measurements of $\mathrm{Cu}, \mathrm{Pb}, \mathrm{Cd}$, and $\mathrm{Zn}$ were performed in situ using the VIP system in Lake Greifen and on site using the VIA-Field in Furtbach and River Wyre (18), both coupled to an on-line deoxygenating module (34). The VIP system was deployed at the 2.5 and $5 \mathrm{~m}$ depths of the lake oxic epilimnion on 2 and 4 September 2003. Three replicate measurements were performed at both depths. For measurements in Furtbach, the VIA-Field was installed in the protected area and the samples were pumped from the polypropylene container. Automatic GIME measurements were performed at a time interval of $1 \mathrm{~h} 30 \mathrm{~min}$ from 3 to 5 September 2003. In Wyre, the VIA-Field was installed on the river bank and samples were pumped directly from the river. Replicate measurements were performed during few hours on 20 and 21 April 2004.

A detailed description of the VIP- and VIA-Field-systems and of the experimental conditions is given in the Supporting Information. The detection limits with both systems, based on a signal-to-noise ratio of 2 , were $0.15 \mathrm{nM} \mathrm{Cu}, 0.01 \mathrm{nM} \mathrm{Pb}$, $0.02 \mathrm{nM} \mathrm{Cd}$, and $0.2 \mathrm{nM} \mathrm{Zn}$, respectively, using a deposition time of $30 \mathrm{~min}$.

Field Donnan Membrane Technique (DMT). Free metal ion concentrations were measured by the Donnan membrane technique using cells designed for in situ measurements. The acceptor side contained $\mathrm{Ca}\left(\mathrm{NO}_{3}\right)_{2}$ with an ionic strength approximately equal to the ionic strength of the surface water and $30 \mathrm{mg} \mathrm{dm}^{-3}$ purified humic acid (35). After 2 to 4 days of in situ exposure, samples were taken from both the donor (in this case, natural water samples) and the acceptor side of the DMT. After measurement of the micro-elements $(\mathrm{Cu}, \mathrm{Pb}, \mathrm{Cd}, \mathrm{Zn}$, and $\mathrm{Ni}$ ) with ICP-MS, the free metal ion concentrations were derived based on either the Donnan membrane equilibrium or on the ion transport kinetics. A more detailed description of DMT is given in the Supporting Information.

PLM Sampling and Handling. Hollow Fiber PLM (HFPLM). HFPLM were deployed in situ. In Lake Greifen, four hollow fibers were deployed at 2.5 and at $5 \mathrm{~m}$ depth for 6 h. In Furtbach, eight hollow fibers were deployed together for 4 h. In River Wyre, five hollow fibers were immersed each time directly in situ. The deployment time in River Wyre was either $2 \mathrm{~h}$ (during the day) or $16 \mathrm{~h}$ (overnight). After 
Environ. Sci. Technol., 40 (6), 1934 -1941, 2006.

deployment, the strip (acceptor) solution inside the HFPLM was removed with a syringe and collected for subsequent analysis by ICP-MS. Details of the membrane preparation and characteristics are given in the Supporting Information (Table S1).

Flow-Through PLM (FTPLM). The measurements were carried out in the laboratory in filtered samples using flow-through cells, as described in ref 23. Metal concentrations in the strip solution were analyzed by ICP-MS. Details of the membrane preparation and of sample handling are given in the Supporting Information.

SCP Measurements. SCP measurements were made with an agarose gelcovered mercury microelectrode (radius ca. $4.5 \times 10^{-6} \mathrm{~m}$ ). The preparation of the gel layer is described in ref 17 and the procedure for polishing of the iridium microelectrode surface and deposition of the mercury layer is detailed in refs 17 , 36, 37. Measurement parameters were deposition time, 1200s; stripping current, $5 \times 10^{-11} \mathrm{~A}$; equilibration time between measurements, $15 \mathrm{~min}$.

CLE-SV Measurements of Cadmium Speciation. Cadmium speciation is evaluated by ligand-exchange with ethylenediamine (EN) and differential pulse stripping voltammetry (DP-SV) measurement of the formed CdEN complexes (28, 38). $\mathrm{Cd}^{2+}$ is calculated based on the equilibria with the CdEN complexes.

EN (1 mM) and Cd(II) (2-55 nM) were added to a series of aliquots of the filtered lake and stream water samples, and these samples were equilibrated overnight. DP-SV was performed the next day. Details of the measurement parameters are given in the Supporting Information. A one-ligand model was used to fit the data within the titration range for the Lake Greifen and the River Wyre samples, using the program FITEQL (39).

\section{Results and Discussion}

Water Composition at the Sampling Sites. $\mathrm{pH}$ was particularly high in the epilimnion of Lake Greifen under the late summer conditions (8.7), whereas lower $\mathrm{pH}$ was observed in Furtbach (8.2-8.5) and in River Wyre (7.7-8.6). River Wyre had a higher DOC content (average $15 \mathrm{mg} \mathrm{dm}^{-3}$ ), which is assumed to consist largely of fulvic acid, than Lake Greifen $\left(4.7 \mathrm{mg} \mathrm{dm}^{-3}\right)$ and Furtbach $\left(1.9 \mathrm{mg} \mathrm{dm}^{-}\right.$ $\left.{ }^{3}\right)$.

Total Dissolved Metal Concentrations. Total dissolved metal concentrations determined by four participating laboratories for both field campaigns are compared in Tables S2, S3, S4, and Figure S1 (Supporting Information) and in Figure 1. Blanks given in Table S2 indicate that some problems may be encountered for the low $\mathrm{Cd}$ and $\mathrm{Pb}$ concentrations. Very good agreement was found between the results of the four laboratories for $\mathrm{Cu}$ concentrations at the three sampling sites (in the range 20-40 nM), as illustrated in Figure 1 for measurements on four successive days in River Wyre. Very low Zn concentrations were measured in Lake Greifen (10-15 nM), whereas higher concentrations were observed in Furtbach (average $63 \mathrm{nM}$ ) and in River Wyre (average $41 \mathrm{nM}$ ). Some variability between the laboratories was found even at the higher $\mathrm{Zn}$

concentrations. The results on $\mathrm{Pb}$ in River Wyre (with an average of $1.3 \mathrm{nM}$ ) from the four laboratories were within a narrow range (Figure 1), whereas the results for Lake Greifen (with an average of 0.15-0.22 nM) and Furtbach (average 0.47 $\mathrm{nM}$ ) were somewhat more variable. The Cd concentrations were very low in Lake Greifen and in Furtbach (0.04-0.1 nM), and somewhat higher in River Wyre (0.2 $\mathrm{nM})$. Reasonable agreement was obtained between the laboratories at these very 
low levels, which are close to the detection limits. The field-filtered samples of River Wyre were used for the comparison of $\mathrm{Cd}$ with the speciation methods, for which good reproducibility was obtained in duplicate samples (Table S4c).
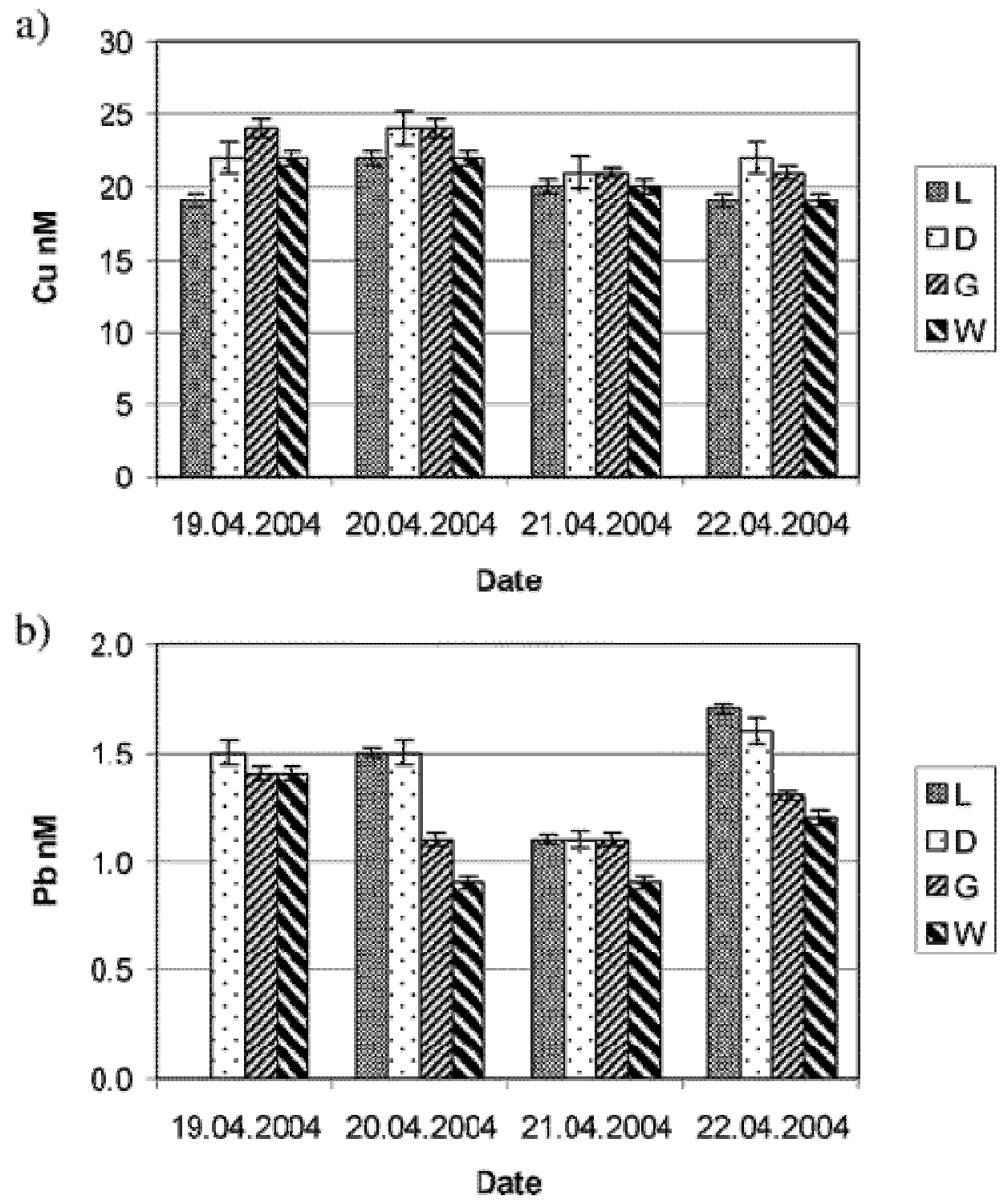

Figure 1 Dissolved concentrations of $\mathrm{Cu}(\mathrm{a})$ and $\mathrm{Pb}(\mathrm{b})$ measured in River Wyre on four successive days by four laboratories using ICP-MS (for detailed data see Table S4, Supporting Information).

Reliability of the Sensor Methods. DGT. Using DGT, $\mathrm{Cu}, \mathrm{Zn}, \mathrm{Cd}, \mathrm{Pb}$, and $\mathrm{Ni}$ were measured in Lake Greifen, Furtbach, and River Wyre (Tables $๗ 1$ and 2). The blank values are summarized in Table S2, as blank concentrations per gel unit, which include the metals contained in the blank gels and the sample handling blanks. Reasonable reproducibility of the DGT measurements was observed within laboratory and also between different laboratories, particularly in the samples from River Wyre (Tables 1 and 2, and Table S5, Supporting Information). Very low $\mathrm{Pb}$ levels in Lake Greifen showed more variability. $\mathrm{Zn}$ and $\mathrm{Cd}$ could not be reliably measured at the very low levels in Lake Greifen. Mn, Fe, and $\mathrm{Al}$ were also measured in River Wyre (Table 2). 
Environ. Sci. Technol., 40 (6), 1934 -1941, 2006.

GIME-SW-SV. Very low blank values were measured, which are usually below the detection limit of the method (Table S2). As the measurements are carried out directly in the natural water, problems of sample handling are minimized. Good sensitivity and reproducibility was obtained for $\mathrm{Cu}, \mathrm{Zn}, \mathrm{Cd}$, and $\mathrm{Pb}$, even at very low levels (Tables 1 and 2). Table S6 (Supporting Information) illustrates the reproducibility for successive measurements in River Wyre, in which both analytical uncertainties and temporal variations in the river are included. Good agreement for $\mathrm{Cu}$ in River Wyre was found between in situ measurements and measurements in filtered samples in the laboratory (Table 2).

HFPLM. Blank values of HFPLM are critical for Cd, whereas they represent only a small fraction of the measured concentrations for $\mathrm{Cu}$ and $\mathrm{Pb}$ (Table S2).

Reproducibility between replicate samples was good, as indicated by the standard deviations in Tables 1 and 2. Because of the high preconcentration factor of this device, very low levels of $\mathrm{Cu}, \mathrm{Cd}$, and $\mathrm{Pb}$ are reached.

FTPLM. For FTPLM measurements carried out in the laboratory, blank values represent for $\mathrm{Cu}<5 \%$ of the measured concentrations in the strip solution (Table S2). Reasonable reproducibility between replicates was observed for Cu (Tables 1 and 2).

DMT. DMT samplers deployed in the three systems gave results for $\mathrm{Cu}, \mathrm{Cd}, \mathrm{Pb}$, and $\mathrm{Ni}$. The blank values include here blanks of the humic acids used in the acceptor compartment and sample handling (Table S2). Reasonable reproducibility in replicate samples was obtained (Tables 1 and 2).

SCP. Although the SCP blank data were low (Table S2), some problems with contamination were encountered, probably due to sample handling in the laboratory. Only a few results considered reliable for $\mathrm{Cu}$ are reported.

CLE-SV. Very low free $\mathrm{Cd}^{2+}$ concentrations are determined based on measurement of labile $\mathrm{Cd}$ and equilibrium calculations. Blank values of labile $\mathrm{Cd}$ were below the detection limit. Errors were estimated based on the titration curve with $\mathrm{Cd}$. No reliable results were obtained in Furtbach, in which apparently strong complexation and slow ligand-exchange kinetics occurred, so that no labile $\mathrm{Cd}$ was detected even after Cd addition.

\section{Measured Trace Metal Concentrations Using the Various Analytical}

Techniques. The measured metal concentrations using the various methods are summarized in Tables 1 and 2 and in Figure 2. The ICP-MS values for comparison with the speciation methods are averaged over those measured by the various laboratories and over the sampling periods. The DGT, PLM, and DMT results all represent averages over the exposure time periods indicated in the tables. The GIME-VIP results in the lake are averages of a set of measurements performed over several hours. In Furtbach, the data shown for GIME-VIA-FIELD in the tables are averages of 36 measurements over $48 \mathrm{~h}$, and in River Wyre, averages over 9 measurements over 1 day. Obviously contaminated values (higher than dissolved) are marked in the tables. 

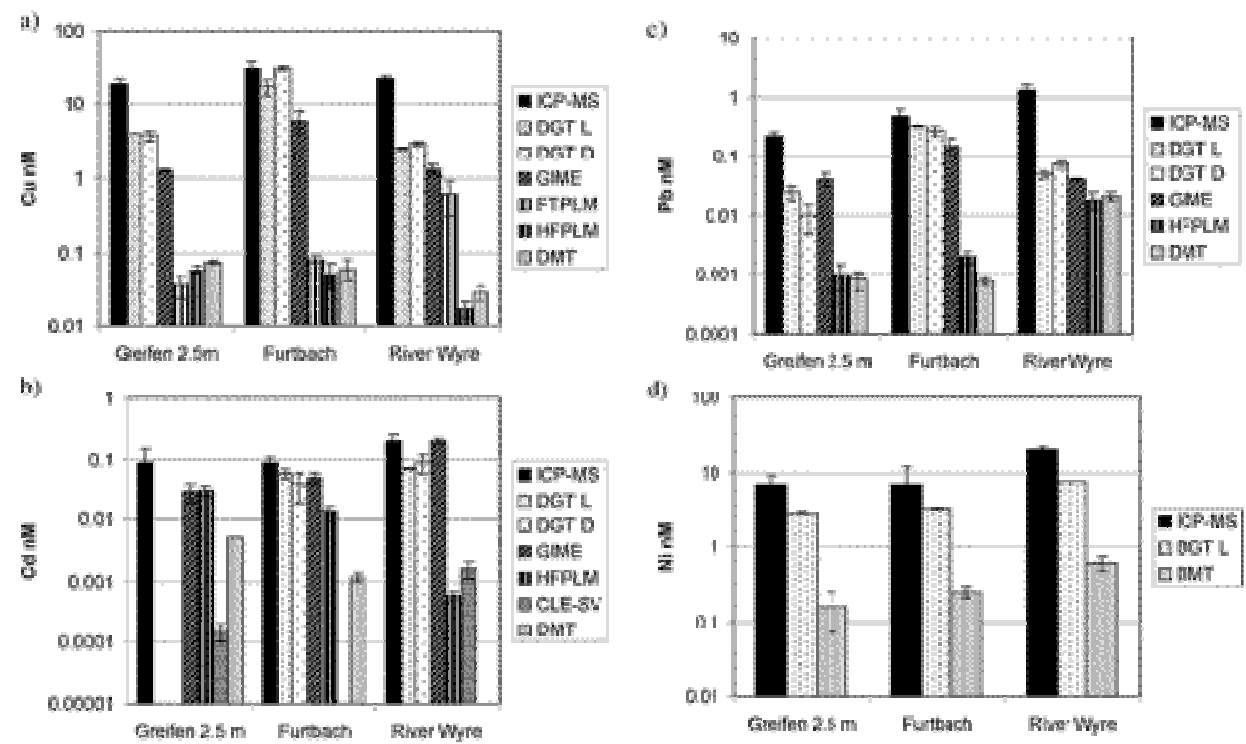

Figure 2 Measured concentrations of $\mathrm{Cu}(\mathrm{a}), \mathrm{Cd}(\mathrm{b}), \mathrm{Pb}(\mathrm{c})$, and $\mathrm{Ni}(\mathrm{d})$ in Lake Greifen $(2.5 \mathrm{~m})$, Furtbach and River Wyre using the techniques ICP-MS (average), DGT, GIME, FTPLM, HFPLM, DMT, and CLE-SV (for detailed data see Tables 1 and 2).

Copper was detectable in all samples with all the methods used. The measured concentrations decreased in the order DGT > GIME > SCP > HFPLM $\approx$ FTPLM $\approx$ DMT (Tables 1, 2, and Figure 2). Close results by DGT were obtained by two laboratories. The dynamic $\mathrm{Cu}$ species measured by GIME were somewhat lower than the DGT results, with very good reproducibility at different times. Dynamic $\mathrm{Cu}$ species were measured by FTPLM in river Wyre since the permeability criterion ( $\Perp$ ) value was in the range $0.4<\boldsymbol{\iota}<0.8$ (see Supporting Information), whereas free metal ion (and possibly lipophilic species) were measured by FTPLM $(0.04<$ $\pi<0.1)$ in Lake Greifen and Furtbach stream, and by HFPLM $(0.005<\pi<0.02)$ in all cases. DMT and HFPLM values were orders of magnitude lower than the total dissolved $\mathrm{Cu}$ in all three systems, and in similar systems. This tends to confirm that free metal ion concentration was measured by both systems, and that lipophilic Cu complexes (which might increase the HFPLM result) were negligible in these cases.

Overall, these results indicate that $\mathrm{Cu}$ was strongly complexed with natural organic matter in all three systems. The greater amount of metal species measured by DGT is consistent with the longer effective time scale of this technique as compared to the GIME (10). The relatively small fluxes of dynamic $\mathrm{Cu}$ (resulting in apparent small fraction of total $\mathrm{Cu}$ ) measured by all dynamic techniques are likely due to the lower diffusion coefficients of fulvic or humic complexes compared to $\mathrm{Cu}^{2+}$, as discussed more quantitatively in the companion manuscript (32).

Zinc. Only few reliable results were obtained for $\mathrm{Zn}$, due to problems with the detection limits of some of the methods and with contamination (Tables 1 and 2). Using DGT, Zn was detected in all samples, but the very low concentrations in Lake Greifen were not reliably measured. In Furtbach, the DGT values observed by both laboratories were higher than the average total dissolved concentrations, which may be due to the different sampling times of the DGT and total dissolved measurements, combined to highly variable $\mathrm{Zn}$ concentrations, and possibly to contamination problems (Table 1 ). More consistent results for $\mathrm{Zn}$ were obtained 
Environ. Sci. Technol., 40 (6), 1934 -1941, 2006.

by DGT and by GIME in River Wyre (Table 2). These results indicate that there may be strong $\mathrm{Zn}$ complexation in Lake Greifen and less extensive complexation in Furtbach and in River Wyre.

Cadmium was near or below the limit of detection of several of the methods. The results in Tables 1 and 2 and Figure 2 nevertheless indicate that detected $\mathrm{Cd}$ decreased in the order DGT :GGIME > HFPLM > DMT > CLE-SV, consistent with the kinetic windows of these techniques. Cd was below detection for DGT in the lake at low total concentrations $(<0.1 \mathrm{nM})$, but was detected in Furtbach and in River Wyre. GIME-VIP and GIME-VIA-FIELD detected Cd very sensitively in all samples. Cd measured by GIME-VIA in Wyre was high in comparison to the other methods and to the total $\mathrm{Cd}$ and may have been influenced by contamination. Cd detected by HFPLM was controlled by the free metal ions in all cases, as indicated by the perme ability criterion values $\left(3 \times 10^{-4}<\pi<0.04\right)$. The high Cd values obtained in hard waters (Lake Greifen and Furtbach) were probably linked to the presence of a large proportion of $\mathrm{Cd}$ as $\mathrm{CdCO}_{3}{ }^{0}(32)$, which can diffuse freely through the PLM due to its neutrality (lipophilic complexes). The measured flux is thus the sum of that of $\mathrm{Cd}^{2+}$ and $\mathrm{CdCO}_{3}{ }^{\circ}$. In River Wyre carbonate complexes are negligible, and HFPLM only measures free ions, in accordance with DMT and CLESV data. DMT and CLE-SV gave low values of free $\mathrm{Cd}^{2+}$ in all three systems. The free $\mathrm{Cd}^{2+}$ in Furtbach could not be detected by CLE-SV, probably due to the presence of high concentrations of strong complexing ligands.

Overall, these results indicate that $\mathrm{Cd}$ was present in a significant proportion as dynamic complexes, since sizable fractions of Cd were detected by DGT and by GIME in all three systems (see model results in ref 32). However, DMT and CLESV, as well as HFPLM for River Wyre, revealed low values of free $\mathrm{Cd}^{2+}$, showing a significant complexation strength.

Lead was detected in a very low concentration range by most methods (Tables 1 and 2 and Figure 2). Considering the relatively large errors, overall, the measured $\mathrm{Pb}$ concentrations followed the order DGT $\approx$ GIME $>$ HFPLM $\approx D M T$. According to the permeability criterion $(0.01<\boldsymbol{\jmath}<0.2$ in all cases) it is expected that HFPLM measures free $\mathrm{Pb}^{2+}$. The reported concentrations were indeed much lower than those obtained with DGT and GIME in all waters, and similar to DMT data.

Interesting differences in $\mathrm{Pb}$ speciation were thus observed in the three systems. $\mathrm{Pb}$ appeared to be strongly complexed both in Lake Greifen and in Furtbach. However, both DGT and GIME measured a higher flux in Furtbach (or a higher apparent fraction of total $\mathrm{Pb}$ ), which suggests that the complexes were more dynamic (mobile and labile) in Furtbach than in Lake Greifen. In Wyre, the fluxes of dynamic Pb detected by DGT and GIME were low, in good agreement between these two methods, whereas free $\mathrm{Pb}^{2+}$ by HFPLM and DMT was relatively high. These results are in line with the interpretation that $\mathrm{Pb}$ is not bound to organics in Wyre, but rather to colloidal Fe, $\mathrm{Mn}$, and $\mathrm{Al}$ (see ref 32 for modeling evidence). Such colloidal species would not be mobile enough to be detected by DGT or $\mathrm{GIME}$, i.e., they would not belong to the dynamic fraction of $\mathrm{Pb}$ for these techniques.

Nickel was only measured by DGT and by DMT (Tables 1 and 2, Figure 2). In all cases, the concentrations measured by DGT were much higher than those measured by DMT, in agreement with measurements of labile species by DGT and of free metal ions by DMT.

These results indicate some differences in metal speciation between the three water systems. In Furtbach with low DOC, higher dynamic concentrations of $\mathrm{Cu}$, $\mathrm{Zn}, \mathrm{Cd}, \mathrm{Pb}$, and $\mathrm{Ni}$ were observed than in Lake Greifen and in River Wyre. Low 
Environ. Sci. Technol., 40 (6), 1934 -1941, 2006.

labile $\mathrm{Pb}$ in River Wyre were probably due to the influence of colloidal species. These features are further discussed in comparison to modeling results in (32).

Performance of the Analytical Techniques. All the methods could be used in these freshwater samples, under both hardwater and softwater conditions.

Difficulties were mostly encountered with respect to the very low concentra tion levels, which fell below the detection limits in some cases. It is clearly advantageous that all methods involve a preconcentration step, by accumulation at the electrode for the electrochemical methods, or in the acceptor medium in the case of DGT, DMT, and PLM. Further improvements with regard to preconcentration factors and to detection limits due to blanks are necessary to measure reliably the very low concentrations encountered in pristine freshwaters.

The in situ methods clearly have an advantage for measurements of speciation without problems of sample handling and of filtration, which may induce changes in the samples and may introduce artifacts. The accumulation time of each method determines the time-average over which its characteristic dynamic species are measured. Thus GIME provides time-averages of the order of minutes, DGT gives a measure of the average flux on the time scale of days, and PLM may provide averages on the order of hours to days.

The concentrations detected by the various methods are in broad agreement with the theoretical expectations $(10,32)$. Each technique has its characteristic lability criterion which determines the operationally dynamic metal species that it will measure (10). The detected concentrations for $\mathrm{Cu}, \mathrm{Pb}$, and $\mathrm{Cd}$ decrease in the order: DGT $\geq$ GIME $>$ FTPLM $\geq$ HFPLM $\approx$ DMT, which follows the order of decrease in effective measurement time of the techniques. The DGT and GIME devices detect any $\mathrm{Cu}, \mathrm{Zn}, \mathrm{Cd}$, and $\mathrm{Pb}$ species which are dynamic enough in the time-scale of these techniques $(18,40,41)$. Because the time scale is somewhat smaller for GIME, the fraction of total metal measured by GIME is expected to be somewhat smaller than for DGT, which is often observed. In both cases metals bound to colloids or larger molecules of dissolved organic matter will diffuse with a smaller diffusion coefficient than free ion which results in apparently lower proportions of total metal detected by the techniques $(15,32)$. Reasonable agreement between the DGT results of two laboratories was observed, indicating that reproducible DGT results may be obtained by different groups. However, the necessity of working under clean-laboratory conditions for reliable DGT results is evident. Apart from Cd in hardwater, HFPLM and DMT gave similar and low concentrations of $\mathrm{Cu}, \mathrm{Cd}$, and $\mathrm{Pb}$, which should correspond to the free metal ion concentrations. However, the results by DMT were higher than those obtained by CLE-SV for $\mathrm{Cd}^{2+}$, and free $\mathrm{Cu}^{2+}$ previously measured in Lake Greifen by CLE-AdSV (28), suggesting that the CLE-AdSV data may not have been obtained under bulk equilibrium conditions $(29,30)$. FTPLM and HFPLM are complementary, as they may provide different information depending on the conditions defined by the permeability criterion. Either dynamic species (in practice rather by FTPLM) or the sum of free ion and of lipophilic complexes may be measured, since the latter can diffuse freely through the PLM (42). The lipophilic complexes alone may be measured by using the PLM without carrier.

Extensive experience of the application to natural waters has already been gained by DGT $(15,43)$ and GIME-VIP $(18,34,40)$, whereas DMT and PLM have been used here for the first time under natural conditions. A detailed discussion of the results in comparison to the modeled speciation of these metals is presented in the companion manuscript (32). Implications of these analytical techniques for bioavailability of metals are discussed in ref 10 . 
Environ. Sci. Technol., 40 (6), 1934 -1941, 2006.

The use of several analytical methods in the same system provides useful comparisons of metal speciation with respect to the presence of various kinds of dynamic species and to the fraction of free aqueous ions. Depending on the questions to be examined, several of the methods described here may be applied to gain insight into metal speciation.

\section{Acknowledgment}

This work was performed within the framework of the BIOSPEC project funded by the European Commission's RTD Program "Preserving the Ecosystem" (Key Action Sustainable Management and Quality of Water), under contract EVK1-CT-200100086.

\section{Supporting Information Available}

Experimental part, six tables, and references. This material is available free of charge via the Internet at http://pubs.acs.org.

* Corresponding author phone: +41448235494 ; fax: +41448235311 ; e-mail: laura.sigg@eawag.ch.

tEawag, Swiss Federal Institute for Aquatic Science and Technol ogy.

fUniversity of Lancaster.

SUniversity of Geneva.

$\perp$ Rijksinstituut voor Volksgezondheid en Milieu.

Universitat de Lleida.

\&Wageningen University.

oUniversity of Southern Denmark. 
Environ. Sci. Technol., 40 (6), 1934 -1941, 2006.

\section{References}

1. Campbell, P. G. C. Interactions between trace metals and aquatic organisms: a critique of the freeion activity model. In Metal Speciation and Bioavailability in Aquatic Systems; Tessier, A., Turner, D. R., Eds.; John Wiley \& Sons: Chichester, 1995; pp 45-102.

2. Campbell, P. G. C.; Errécalde, O.; Fortin, C.; Hiriart-Baer, V. P.; Vigneault, B. Metal bioavailability to phytoplankton-applicability of the biotic ligand model. Comp. Biochem. Physiol., Part C 2002, 133, 189-206.

3. Sunda, W. G.; Huntsman, S. A. Processes regulating cellular metal accumulation and physiological effects: Phytoplankton as model systems. Sci. Tot. Environ. 1998, 219, 165-181.

4. Paquin, P. R.; Gorsuch, J. W.; Apte, S. A.; Batley, G. E.; Bowles, K. C.; Campbell, P. G. C.; Delos, C. G.; Di Toro, D. M.; Dwyer, R. L.; Glavez, F.; Gensenmer, R. W.; Goss, G. G.; Hogstrand, C.; Janssen, C. R.; McGeer, J. C.; Naddy, R. B.; Playle, R. C.; Santore, R. C.; Schneier, U.; Stubblefield, W.; Wood, C. M.; Wu, K. B. The biotic ligand model: a historical overview. Comp. Biochem. Phys., Part C 2002, 133, 3-35.

5. Van Leeuwen, H. P. Metal speciation dynamics and bioavail ability: inert and labile complexes. Environ. Sci. Technol. 1999, 33, 3743-3748.

6. Wilkinson, K. J.; Buffle, J. Critical evaluation of physicochemical parameters and processes for modeling the biological uptake of trace elements in environmental (aquatic) systems. In Kinetics and Transport at Biointerfaces; Van Leeuwen, H. P., Köster, W., Eds.; John Wiley \& Sons: 2004; Vol. 9, pp 445-533.

7. Galceran, J.; Van Leeuwen, H. P. Dynamics of biouptake processes. In Kinetics and Transport at Biointerfaces; Van Leeuwen, H. P., Köster, W., Eds.; John Wiley \& Sons: 2004; Vol. 9, pp 147-203.

8. Tipping, E. Cation Binding by Humic Substances; Cambridge University Press: Cambridge, 2002.

9. Buffle, J. Complexation Reactions in Aquatic Systems: An Analytical Approach; Ellis Horwood limited: Chichester, 1988.

10. Van Leeuwen, H. P.; Town, R. M.; Buffle, J.; Cleven, R. F. M. J.; Davison, W.; Puy, J.; Van Riemsdijk, W. H.; Sigg, L. Dynamic speciation analysis and bioavailability of metals in aquatic systems. Environ. Sci. Technol. 2005, 39, 8545-8556.

11. In Situ Monitoring of Aquatic Systems; Chemical Analysis and Speciation; Buffle, J.; Horvai, G., Eds.; Wiley: 2000.

12. Environmental Electrochemistry. Analyses of Trace Element Biogeochemistry; Taillefert, M.; Rozan, T. F., Eds.; American Chemical Society: Washington, DC, 2002; Vol. 811.

13. Davison, W.; Zhang, $H$. In situ speciation of trace components in natural waters using thin-film gels. Nature 1994, 367, 546-548.

14. Zhang, H.; Davison, W. Performance characteristics of diffusion gradients in thin films for the in situ measurements of trace metals in aqueous solution. Anal. Chem. 1995, 67, 3391-3400.

15. Zhang, H.; Davison, W. Direct in situ measurements of labile inorganic and organically bound metal species in synthetic solutions and natural waters using diffusive gradients in thin films. Anal. Chem. 2000, 72, 4447-4457.

16. Belmont-Hébert, C.; Tercier, M.-L.; Buffle, J.; Fiaccabrino, G. C.; Koudelka-Hep, M. Gel-integrated microelectrode arrays for direct voltammetric measurements of heavy metals in natural waters an other complex media. Anal. Chem. 1998, 70, 2949-2956.

17. Tercier, M.-L.; Buffle, J. Antifouling membrane-covered voltammetric microsensor for in situ measurements in natural waters. Anal. Chem. 1996, 68, 3670-3678. 
Environ. Sci. Technol., 40 (6), 1934 -1941, 2006.

18. Tercier-Waeber, M.-L.; Buffle, J.; Koudelka-Hep, M.; Graziottin, F. Submersible voltammetric probes for real-time continuous monitoring of trace elements in natural aquatic systems. In Environmental Electrochemistry. Analyses of Trace Element Biogeochemistry; Taillefert, M., Rozan, T. F., Eds.; American Chemical Society: Washington, DC, 2002; Vol. 811, pp 16-39.

19. Pei, J.; Tercier-Waeber, M.-L.; Buffle, J. Simultaneous deter mination and specation of zinc, cadmium, lead and copper in natural water with minimum handling and artifacts, by voltammetry on a gel-integrated microelectrode array. Anal. Chem. 2000, 72, 161-171.

20. Van Leeuwen, H. P.; Town, R. M. Electrochemical metal speciation analysis of chemically heterogeneous samples: the outstanding features of stripping chronopotentiometry at scanned deposition potential. Environ. Sci. Technol. 2003, 37, 3945-3952.

21. Town, R. M.; Van Leeuwen, H. P. Depletive stripping chronopotentiomery: a major step forward in electrochemical stripping techniques for metal ion speciation analysis. Electroanalysis 2004, 16, 458471.

22. Parthasarathy, N.; Pelletier, M.; Buffle, J. Hollow fiber based supported liquid membrane: a novel analytical system for trace metal analysis. Anal. Chim. Acta 1997, 350, 183-195.

23. Tomaszewski, L.; Buffle, J.; Galceran, J. Theoretical and analytical characterization of a flowthrough permeation liquid membrane with controlled flux for metal speciation measurements. Anal. Chem. 2003, 75, 893-900.

24. Salaun, P.; Buffle, J. Integrated microalanytical system coupling permeable liquid membrane and voltammetric detection for trace metal speciation. Theory and applications. Anal. Chem. 2004, 76, 3139.

25. Buffle, J.; Parthasarathy, N.; Djane, N. K.; Matthiasson, L. Permeation Liquid Membrane for Field Analysis and Speciation of Trace Compounds in Waters. In In Situ Monitoring of Aquatic Systems, Chemical Analysis and Speciation; Buffle, J., Horvai, G., Eds.; Wiley: 2000.

26. Temminghoff, E. J. M.; Plette, A. C. C.; Van Eck, R.; Van Riemsdijk, W. H. Determination of the chemical speciation of trace metals in aqueous systems by the Wageningen Donnan membrane technique. Anal. Chim. Acta 2000, 417, 149-157.

27. Weng, L. P.; Van Riemsdijk, W. H.; Temminghoff, E. J. M. Kinetic aspects of DMT for measuring free metal ion concentrations. Anal. Chem. 2005, 77, 2852-2861.

28. Xue, H.; Sigg, L. A review of competitive ligand-exchange/voltammetric methods for speciation of trace metals in freshwater. In Environmental Electrochemistry: Analyses of Trace Element

Biogeochemistry; Rozan, T. F., Taillefert, M., Eds.; American Chemical Society: Washington, 2002; Vol. 811, pp 336-370.

29. van Leeuwen, H. P.; Jansen, S. Dynamic aspects of metal speciation by competitive ligand exchange-adsorptive stripping voltammetry (CLE-AdSV). J. Electroanal. Chem. 2005, 579, 337-342.

30. Van Leeuwen, H. P.; Town, R. M. Kinetic limitations in measuring stabilities of metal complexes by competitive ligand exchange-adsorptive stripping voltammetry (CLE-AdSV). Environ. Sci. Technol. 2005, 39, 7217-7225.

31. Parthasarathy, N.; Pelletier, M.; Buffle, J. The use of permeation liquid membrane (PLM) as an analytical tool for trace metal speciation studies in natural waters. J. Phys. IV 2003, 107, 1021-1024.

32. Unsworth, E.; Warnken, K. W.; Zhang, H.; Davison, W.; Black, F.; Buffle, J.; Cao, J.; Cleven, R. F. M. J.; Galceran, J.; Gunkel, P.; Kalis, E. J. J.; Kistler, D.; Van Leeuwen, H. P.; Martin, M.; Noel, S.; Nur, Y.; Odzak, N.; Puy, J.; Van Riemsdijk, W. H.; Sigg, L.; Temminghoff, E. J. M.; Tercier-Waeber, M.-L.; Toepperwien, S.; Town, R. M.; Weng, L. P.; Xue, H. Model predictions of metal speciation in freshwaters measured by in situ techniques. Environ. Sci. Technol. 2006, 40, ****. 
Environ. Sci. Technol., 40 (6), 1934 -1941, 2006.

34. Tercier-Waeber, M.-L.; Buffle, J. Submersible online oxygen removal system coupled to an in situ voltammetric probe for trace element monitoring in freshwater. Environ. Sci. Technol. 2000, 34, 40184024.

35. Kalis, E. J. J.; Weng, L. P.; Dousma, F.; Temminghoff, E. J. M.; van Riemsdijk, W. H. Measuring free metal ion concentrations in-situ in natural waters using Donnan Membrane Technique. Environ. Sci. Technol. 2006, 40, 955-961.

36. Tercier, M.-L.; Parthasarathy, N.; Buffle, J. Reproducible, reliable and rugged Hg-plated Ir-based microelectrode for in situ measurements in natural waters. Electroanalysis 1995, 7, 55-63.

37. van Leeuwen, H. P.; Town, R. M. Stripping chronopotentiometry for metal ion speciation analysis at a microelectrode. J. Electroanal. Chem. 2002, 523, 16-25.

38. Xue, H. B.; Sigg, L. Cd speciation and complexation by natural organic ligands in freshwater. Anal. Chim. Acta 1998, 363, 249-259.

39. Westall, J. C. FITEQL, A program for the determination of chemical equilibrium constants from experimental data; Department of Chemistry, Oregon State University: Oregon, 1982.

40. Buffle, J.; Tercier-Waeber, M.-L. In situ voltammetry: concepts and practice for trace analysis and speciation. In In Situ Monitoring of Aquatic Systems; Chemical Analysis and Speciation; Buffle, J., Horvai, G., Eds.; J. Wiley \& Sons: Chichester, 2000; Vol. 6, p 623.

41. Davison, W.; Fones, G.; Harper, M.; Teasdale, P.; Zhang, H. Dialysis, DET and DGT: in situ diffusional techniques for studying water, sediments and soils. In In situ chemical monitoring of aquatic systems: chemical analysis and specia tion; Buffle, J., Horvai, G., Eds.; Wiley: Chichester, 2000.

42. Parthasarathy, N.; Pelletier, M.; Buffle, J. Permeation liquid membrane for trace metal speciation in natural waters. Transport of liposoluble Cu(II) complexes. J. Chromatogr. A 2004, 1025, 33-40.

43. Gimpel, J.; Zhang, H.; Davison, W.; Edwards, A. In situ trace metal speciation in lake surface waters using DGT, dialysis, and filtration. Environ. Sci. Technol. 2003, 37, 138-146. 
Environ. Sci. Technol., 40 (6), 1934 -1941, 2006.

Table 1: Comparison of Metal Concentrations Measured by the Various Techniques in Lake Greifen and in Furtbach (all data in nM) ${ }^{a}$ Lake

Greifen, $2.5 \mathrm{~m}$

\begin{tabular}{|c|c|c|c|c|c|c|c|}
\hline method & lab & date & $\mathrm{Cu}$ & $\mathrm{Zn}$ & $\mathrm{Cd}$ & $\mathrm{Pb}$ & $\mathrm{Ni}$ \\
\hline ICP-MS & average & $\begin{array}{l}2 \& \\
4 / 09 / 03\end{array}$ & $19 \pm 3$ & $10 \pm 4$ & $0.09 \pm 0.06$ & $0.22 \pm 0.03$ & $7 \pm 2$ \\
\hline DGT & Lancaster & $1-4 / 9 / 03$ & $4.0 \pm 0.03$ & $\begin{array}{l}0.6 \pm \\
2.6\end{array}$ & $<\mathrm{dl}$ & $\begin{array}{l}0.024 \pm \\
0.006\end{array}$ & $\begin{array}{l}2.7 \pm \\
0.1\end{array}$ \\
\hline DGT & Duebendorf & $1-4 / 9 / 03$ & $3.8 \pm 0.6$ & $\begin{array}{l}0.4 \pm \\
0.4\end{array}$ & $<0.009$ & $0.01 \pm 0.01$ & na \\
\hline DGT & Bilthoven & $1-4 / 9 / 03$ & 8.6 & na & $*$ & $*$ & na \\
\hline GIME & Geneva & $02 / 09 / 2003$ & $\begin{array}{l}1.22 \pm \\
0.05\end{array}$ & na & $0.03 \pm 0.01$ & $*$ & na \\
\hline GIME & Geneva & $04 / 09 / 2003$ & $1.3 \pm 0.2$ & na & $0.02 \pm 0.00$ & $0.04 \pm 0.01$ & na \\
\hline SCP & Belfast & $02 / 09 / 2003$ & 0.04 & na & na & $*$ & na \\
\hline SCP & Belfast & $04 / 09 / 2003$ & 0.77 & na & na & $*$ & na \\
\hline FTPLM & Geneva & $02 / 09 / 2003$ & $\begin{array}{l}0.035 \pm \\
0.012\end{array}$ & na & na & na & na \\
\hline FTPLM & Geneva & $04 / 09 / 2003$ & \begin{tabular}{|l|}
$0.05 \pm$ \\
0.02
\end{tabular} & na & na & $*$ & na \\
\hline HFPLM & Geneva & $2 \& 4 / 9 / 03$ & $\begin{array}{l}0.057 \pm \\
0.009\end{array}$ & na & $0.031 \pm 0.006$ & $\begin{array}{l}0.001 \pm \\
0.0005\end{array}$ & na \\
\hline DMT & Wageningen & $1-4 / 9 / 03$ & $\begin{array}{l}0.073 \pm \\
0.005\end{array}$ & na & \begin{tabular}{|l|}
$0.0051 \pm$ \\
0.00003
\end{tabular} & $\begin{array}{l}0.0008 \pm \\
0.0003\end{array}$ & $\begin{array}{l}0.16 \pm \\
0.09\end{array}$ \\
\hline CLE-SV & Duebendorf & $02 / 09 / 2003$ & na & na & $\begin{array}{l}0.00015 \pm \\
0.00005\end{array}$ & na & na \\
\hline CLE-SV & Duebendorf & $04 / 09 / 2003$ & na & na & $\begin{array}{l}0.00010 \pm \\
0.00005\end{array}$ & na & na \\
\hline \multicolumn{8}{|c|}{$\begin{array}{l}\text { Lake Greifen, } \\
5.0 \mathrm{~m}\end{array}$} \\
\hline method & lab & date & $\mathrm{Cu}$ & $\mathrm{Zn}$ & $\mathrm{Cd}$ & $\mathrm{Pb}$ & $\mathrm{Ni}$ \\
\hline ICP-MS & average & $\begin{array}{l}2 \& \\
4 / 09 / 03\end{array}$ & $19 \pm 4$ & $13 \pm 6$ & $0.07 \pm 0.02$ & $0.15 \pm 0.05$ & $6 \pm 2$ \\
\hline DGT & Lancaster & $1-4 / 9 / 03$ & $4.5 \pm 0.5$ & $*$ & $<\mathrm{dl}$ & $0.01 \pm 0.01$ & $\begin{array}{l}3.1 \pm \\
0.3\end{array}$ \\
\hline DGT & Duebendorf & $1-4 / 9 / 03$ & $11.3 \pm 0.8$ & $\begin{array}{l}4.8 \pm \\
1.8\end{array}$ & $<0.009$ & $0.04 \pm 0.02$ & na \\
\hline GIME & Geneva & $02 / 09 / 2003$ & $\begin{array}{l}1.83 \pm \\
0.04\end{array}$ & na & $0.02 \pm 0.01$ & $*$ & na \\
\hline GIME & Geneva & $04 / 09 / 2003$ & $1.7 \pm 0.3$ & na & $0.03 \pm 0.00$ & $0.05 \pm 0.01$ & na \\
\hline SCP & Belfast & $04 / 09 / 2003$ & 0.43 & 3.5 & na & $*$ & na \\
\hline FTPLM & Geneva & $02 / 09 / 2003$ & \begin{tabular}{|l|}
$0.04 \pm$ \\
0.01
\end{tabular} & na & na & na & na \\
\hline FTPLM & Geneva & $04 / 09 / 2003$ & $\begin{array}{l}0.05 \pm \\
0.02\end{array}$ & na & na & na & na \\
\hline HFPLM & Geneva & $2 \& 4 / 9 / 03$ & $\begin{array}{l}0.048 \pm \\
0.015\end{array}$ & na & $0.031 \pm 0.016$ & $\begin{array}{l}0.002 \pm \\
0.0005\end{array}$ & na \\
\hline DMT & Wageningen & $1-4 / 9 / 03$ & 0.059 & na & 0.0053 & 0.00043 & 0.16 \\
\hline CLE-SV & Duebendorf & $02 / 09 / 2003$ & na & na & $\begin{array}{l}0.00042 \pm \\
0.0001\end{array}$ & na & na \\
\hline CLE-SV & Duebendorf & $04 / 09 / 2003$ & na & na & $\begin{array}{l}0.00022 \pm \\
0.0001\end{array}$ & na & na \\
\hline \multicolumn{8}{|l|}{ Furtbach } \\
\hline method & lab & date & $\mathrm{Cu}$ & $\mathrm{Zn}$ & $\mathrm{Cd}$ & $\mathrm{Pb}$ & $\mathrm{Ni}$ \\
\hline ICP-MS & average & $3 \&$ & $30 \pm 7$ & $63 \pm$ & $0.09 \pm 0.02$ & $0.47 \pm 0.16$ & $7 \pm 5$ \\
\hline
\end{tabular}


Environ. Sci. Technol., 40 (6), 1934 -1941, 2006.

\begin{tabular}{|c|c|c|c|c|c|c|c|}
\hline & & $5 / 09 / 03$ & & 28 & & & \\
\hline DGT & Lancaster & $1-5 / 9 / 03$ & $17 \pm 4$ & $\begin{array}{l}91 \pm \\
26\end{array}$ & $0.06 \pm 0.01$ & $0.32 \pm 0.01$ & $\begin{array}{l}3.3 \pm \\
0.1\end{array}$ \\
\hline DGT & Duebendorf & $1-5 / 9 / 03$ & $30 \pm 2$ & $83 \pm 5$ & $0.04 \pm 0.02$ & $0.27 \pm 0.05$ & na \\
\hline DGT & Bilthoven & $1-4 / 9 / 03$ & 12 & na & * & $*$ & na \\
\hline GIME & Geneva & $3-5 / 9 / 03$ & $6 \pm 2$ & na & $0.05 \pm 0.01$ & $0.15 \pm 0.05$ & na \\
\hline SCP & Belfast & $03 / 09 / 2003$ & 0.04 & na & na & $*$ & na \\
\hline FTPLM & Geneva & $03 / 09 / 2003$ & \begin{tabular}{|l|}
$0.08 \pm$ \\
0.01
\end{tabular} & na & na & na & na \\
\hline FTPLM & Geneva & $05 / 09 / 2003$ & \begin{tabular}{|l|}
$0.07 \pm$ \\
0.01
\end{tabular} & na & na & na & na \\
\hline HFPLM & Geneva & $3 \& 5 / 9 / 03$ & \begin{tabular}{|l|}
$0.05 \pm$ \\
0.02
\end{tabular} & na & $0.013 \pm 0.004$ & $\begin{array}{l}0.002 \pm \\
0.0005\end{array}$ & na \\
\hline DMT & Wageningen & $1-5 / 9 / 03$ & \begin{tabular}{|l|}
$0.04 \pm$ \\
0.02
\end{tabular} & na & $\begin{array}{l}0.0012 \pm \\
0.0002\end{array}$ & $\begin{array}{l}0.00075 \pm \\
0.0001\end{array}$ & $\begin{array}{l}0.25 \pm \\
0.04\end{array}$ \\
\hline CLE-SV & Duebendorf & $03 / 09 / 2003$ & na & na & $<\mathrm{dl}$ & na & na \\
\hline
\end{tabular}

${ }^{a}$ Na: not available; $*$ : contamination suspected; <dl: below detection limit. 
Environ. Sci. Technol., 40 (6), 1934 -1941, 2006.

Table 2: Metal Concentrations in River Wyre ${ }^{a}$ (A) Comparison of Metal Concentrations Measured by the Various Techniques (all data in $\mathbf{n M}$ )

\begin{tabular}{|c|c|c|c|c|c|c|c|}
\hline method & Iab & date/time & $\mathrm{Cu}$ & $\mathrm{Zn}$ & $\mathrm{Cd}$ & $\mathrm{Pb}$ & $\mathrm{Ni}$ \\
\hline ICP-MS & average & $19-22 / 04 / 04$ & $22 \pm 2$ & $\begin{array}{l}41 \pm \\
11 \\
\end{array}$ & \begin{tabular}{|l|}
$0.20 \pm$ \\
0.06
\end{tabular} & $\begin{array}{l}1.3 \pm \\
0.3\end{array}$ & $\begin{array}{l}20.2 \\
\pm 2.2 \\
\end{array}$ \\
\hline DGT & Lancaster & $19-22 / 04 / 04$ & $\begin{array}{l}2.5 \pm \\
0.05\end{array}$ & $\begin{array}{l}11 \pm \\
2\end{array}$ & $\begin{array}{l}0.071 \pm \\
0.001\end{array}$ & $\begin{array}{l}0.048 \\
\pm \\
0.006\end{array}$ & $\begin{array}{l}7.5 \pm \\
0.3\end{array}$ \\
\hline DGT & Duebendorf & $19-22 / 04 / 04$ & $\begin{array}{l}2.9 \pm \\
0.2\end{array}$ & $9 \pm 1$ & \begin{tabular}{|l|}
$0.09 \pm$ \\
0.03
\end{tabular} & \begin{tabular}{|l|}
$0.07 \pm$ \\
0.01
\end{tabular} & na \\
\hline DGT & Bilthoven & $19-22 / 04 / 04$ & \begin{tabular}{|l|}
$7.0 \pm$ \\
1.5
\end{tabular} & na & $<\mathrm{dl}$ & \begin{tabular}{|l|}
$0.17 \pm$ \\
0.1
\end{tabular} & na \\
\hline GIME & Geneva & $20 / 04 / 2004$ & $\begin{array}{l}1.24 \pm \\
0.19\end{array}$ & $\begin{array}{l}13 \pm \\
1\end{array}$ & $\begin{array}{l}0.20 \pm \\
0.02\end{array}$ & \begin{tabular}{|l|}
0.041 \\
\pm \\
0.011
\end{tabular} & na \\
\hline GIME & Geneva & $21 / 04 / 2004$ & $\begin{array}{l}1.22 \pm \\
0.10\end{array}$ & $6 \pm 2$ & $\begin{array}{l}0.19 \pm \\
0.05\end{array}$ & $\begin{array}{l}0.044 \\
\pm \\
0.006\end{array}$ & na \\
\hline GIME lab & Geneva & $19 / 04 / 2004$ & $\begin{array}{l}1.21 \pm \\
0.06\end{array}$ & na & * & \begin{tabular}{|l|}
$0.11 \pm$ \\
0.01
\end{tabular} & na \\
\hline FTPLM & Geneva & $20 / 04 / 2004$ & $\begin{array}{l}0.6 \pm \\
0.3\end{array}$ & na & na & $*$ & na \\
\hline FTPLM & Geneva & $21 / 04 / 2004$ & \begin{tabular}{|l|}
$0.28 \pm$ \\
0.05
\end{tabular} & na & na & $*$ & na \\
\hline HFPLM & Geneva & $21 / 04 / 04 \mathrm{am}$ & \begin{tabular}{|l|}
0.017 \\
\pm \\
0.004 \\
\end{tabular} & na & $\begin{array}{l}0.0006 \pm \\
0.0002\end{array}$ & $\begin{array}{l}0.018 \\
\pm \\
0.006\end{array}$ & na \\
\hline HFPLM & Geneva & $21 / 04 / 04 \mathrm{pm}$ & $\begin{array}{l}0.037 \\
\pm \\
0.004\end{array}$ & na & $\begin{array}{l}0.0006 \pm \\
0.0001\end{array}$ & $\begin{array}{l}0.03 \pm \\
0.01\end{array}$ & na \\
\hline HFPLM & Geneva & $\begin{array}{l}21 / 04 / 04 \\
\text { night }\end{array}$ & \begin{tabular}{|l}
0.028 \\
\pm \\
0.001
\end{tabular} & na & $\begin{array}{l}0.0005 \pm \\
0.00002\end{array}$ & $\begin{array}{l}0.016 \\
\pm \\
0.003\end{array}$ & na \\
\hline HFPLM & Geneva & $22 / 04 / 04 \mathrm{am}$ & \begin{tabular}{|l|}
0.028 \\
\pm \\
0.002 \\
\end{tabular} & na & $\begin{array}{l}0.0005 \pm \\
0.00004\end{array}$ & $\begin{array}{l}0.004 \\
\pm \\
0.002 \\
\end{array}$ & na \\
\hline DMT & Wageningen & $19-22 / 04 / 04$ & $\begin{array}{l}0.028 \\
\pm \\
0.006\end{array}$ & na & $<0.001$ & \begin{tabular}{|l|}
0.021 \\
\pm \\
0.003
\end{tabular} & \begin{tabular}{|l}
0.60 \\
\pm \\
0.13
\end{tabular} \\
\hline CLE-SV & Duebendorf & $\begin{array}{l}\text { aver. 19- } \\
22 / 04 / 04\end{array}$ & na & na & $*$ & na & na \\
\hline \multicolumn{8}{|c|}{$\begin{array}{l}\text { (B) Dissolved and DGT labile } \\
\text { concentrations of Mn, Fe, and } \\
\text { Al in River Wyre }\end{array}$} \\
\hline method & lab & date/time & $\mathrm{Mn} n \mathrm{M}$ & Fe $\mathbf{I} \mathbf{M}$ & $\mathrm{Al} \boldsymbol{J} \mathrm{M}$ & & \\
\hline ICP-MS & Lancaster & $19-22 / 04 / 04$ & \begin{tabular}{|l}
$226 \pm$ \\
39
\end{tabular} & $\begin{array}{l}5.2 \pm \\
0.6\end{array}$ & $3.5 \pm 1.3$ & & \\
\hline DGT & Lancaster & $19-22 / 04 / 04$ & $\begin{array}{l}236 \pm \\
7\end{array}$ & \begin{tabular}{|l|}
0.74 \\
\pm \\
0.01
\end{tabular} & $1.6 \pm 0.1$ & & \\
\hline
\end{tabular}

${ }^{a} \mathrm{Na}$ : not available; <dl: below detection limit; * contamination suspected. 